\title{
Orchestrating the digital transformation process through a 'strategy-as-practice' lens: A revelatory case study
}

\author{
Claudia Pelletier, DBA \\ Université du Québec à Trois-Rivières \\ Claudia.Pelletier@uqtr.ca
}

\begin{abstract}
Implementing a digital transformation (DT) strategy constitutes an important challenge for most firms. Small and medium-sized enterprises (SMEs) in particular must be helped in enacting and managing their DT process. To do so, we aim to answer two research questions: What are the dimensions that define a DT strategy in a SME context? And how do these dimensions contribute to the enactment of a DT process in this context? Using an information systems (IS) strategy-as-practice theoretical lens, combined with an information technology (IT) asset orchestration perspective, we opt for an interpretive case study of an industrial service SME whose characteristics are conducive to a renewed vision of IS strategy in a DT context. From this study emerges a process model that allows us to describe and better understand, in a concrete manner, how a DT occurs and how it is managed through a coherent DT strategy.
\end{abstract}

\section{Introduction}

The digital transformation process "involves transformations of key business operations and affects products and processes, as well as organizational structures and management concepts" [1, p. 339]. In its enactment, the DT process must be supported by a coherent DT strategy that tackles the practical issues of governing and implementing the planned DT [2]. In this context, the contribution of IT through appropriate technical and human resources, and completed by the required managerial and IT competencies [3, 4], is vital for companies whose systems and processes are increasingly interconnected with their products and services $[5,6]$.

Now, the strategic role of IT as a vector of higherlevel organizational capabilities [3, 7] has evolved from the functional level to the organizational level through a DT strategy that is meant to support the DT process [8]. An evolution that calls, therefore, for a redefinition of the concept of IS strategy that will better take into account what this evolution implies with regard to the firm's deployment, use and management of IT $[2,9]$. Thus, the DT process

\author{
Louis Raymond, Ph.D. \\ Université du Québec à Trois-Rivières \\ Louis.Raymond@uqtr.ca
}

experienced by companies challenges several premises related to IS strategy and its derived concepts $[6,10]$, and in particular those that are related to the way a DT strategy reshapes IT management practices $[11,12]$.

Although the above observations are shared by both researchers and practitioners, there is as-of-yet no consensus on the conceptualization of a DT strategy [2]. Moreover, there remains a lack of understanding why and how the DT of existing activities can occur [13], and more specifically, what are the specific mechanisms at work in this transformation [3,14].

For SMEs, regardless of their sector of activity or the nature of their activities, this limited identification and understanding of what is a true DT process may have important consequences [15]. Among other things, because technological, managerial and organizational issues may sometimes be experienced more intensely by their actors facing specific contextual contingencies [4, 16]. In other words, facing a DT process that is itself complex by nature [6], what can entrepreneurs and SME managers do to address these important and sometimes underestimated challenges with regard to their firm IS strategy, and specifically with regards to their DT strategy [2]? And consequently, how can SMEs be helped in planning, managing and enacting their DT process? Considering that this help must be provided in coherence with the strategic needs, opportunities and constraints addressed by these firms, and especially in coherence with their specific technological choices [16].

To explore in greater depth the DT phenomenon from a strategic IS standpoint, two research questions have been formulated: What are the dimensions that define a DT strategy in a SME context? And how do these dimensions contribute to the enactment of a DT process in this context? In answer to these questions, we use the strategy-as-practice (S-as-P) theoretical lens to highlight the interactions between the context (praxis), the involved actors (practitioners) as well as their decisions (practices) to explain, in a more concrete manner, how a DT phenomenon occurs [11, 17]. Adapted to the growing complexity of the digital age and well suited to the case study method $[18,19]$, the S-as-P lens is combined to the asset orchestration notion to put forward the specific mechanisms that 
allow a SME to strategically develop, deploy and manage its IT and non-IT resources [14, 20].

Following Yin (2009) and Walsham (2006), a "revelatory" case study founded on the interpretive paradigm has been conducted in an SME that will be called EngSERV ${ }^{1}$. Through two cartographic schemes, the main results of the study lead to a conceptualization of DT in the form of a process model within which the core DT strategy dimensions are underscored. In doing so, the case results highlight the "strategic intent $\rightarrow$ decisions $\rightarrow$ means" sequence [13, 21], as well as different states and important events that occurred over time [22]. More specifically, and as evidenced by the IT management practices observed, the involved actors as well as their focus on specific "strategy sites" [23] have also led to the identification of the three asset allocation mechanisms that work together to enact the expected transformation [1, 24].

The main contributions of this study include the identification of key decisions concerning the enactment of EngSERV's DT, as well as an emergent explanation of these decisions' relationships with other elements of the DT process, especially those concerning the articulation of the DT strategy in today's business context $[2,5]$.

\section{Background}

There are numerous definitions of IS strategy, leading us at present to a rather ambiguous conceptual universe [9]. As the bearer of potentially significant change in the firm's internal activities, communications, relationships and business model [1, 8], the DT process not only challenges several premises related to IS strategy and its derived concepts $[6,10]$, but also introduces new ones such as the DT strategy [2]. As in other complex phenomena related to IT, it is also assumed that the mechanisms, stages, and means by which the DT will be enacted are known and mastered by the firm and its managers [11]. However, this last assumption is false in many cases $[3,5]$, and notably in the case of SMEs [25].

\subsection{IS strategy in a digital world}

Through its general business strategy, its corporate strategy from which emanates the choice of products and services offered, and combined with its competitive strategy, a firm is expected to be able to meet the demands of its business environment and to make the transformation required [6]. In parallel with the evolution of strategic management theories, IS researchers have been interested in the concept of IS

\footnotetext{
1 Alias meant to assure the anonymity of the case studied as well as the case informants.
}

strategy in response to the technological evolution that began in the 1960s. More specifically, through a techno-centric approach that evolved to include the firm's strategic positioning through IS in the 1990s, and culminating with e-business and systems integration in the early $2000 \mathrm{~s}[10]^{2}$. Since then, researchers have focused their attention on the firm's DT as well as its effects on the firm's processes, structures, products and services, and on their "merging" through digital solutions [8, 23]. In this context, IS strategy may thus be (re)defined and studied with different approaches [9]. For example, from perspectives that assign different roles to IT [21, 25].

Now, the main drawback of the IS strategy literature is its focus on strategic planning rather than strategy implementation [2, 17], including who is implementing what, how, and with what consequences [12, p. 69]. Despite a general agreement concerning the importance of IT artefacts and digital solution portfolios as the core of IS strategy [10,26], a second drawback is the lack of consensus with regard to the definition of IS strategy [9], including its associated concepts in the digital age such as the concept of DT strategy [1]. As a consequence, while management consultancies have made the firm's DT strategy their core concern over time [2, p. 1], findings and recommendations from researchers are often ignored because they fail to offer an effective support to firms and practitioners in general [12], and to SMEs and their managers in particular [15].

\subsection{The $S$-as-P theoretical lens in IS research}

Representing an opportunity to better understand why and how the DT of an organization as well as the reconfiguration of its existing activities can occur [13], the S-as-P theoretical lens was put forward in the management field in the late 2000s. From this perspective, strategy has been defined "as a situated, socially accomplished activity, while strategizing comprises those actions, interactions and negotiations of multiple actors and the situated practices that they draw upon in accomplishing that activity" [12, p. 70]. In this theoretical context, the three general parameters of S-as-P are: 1) the practitioners who are the focal strategizing actors; 2) the processes that guide their activities, and 3) the praxis which correspond to the sequence by which activities unfold in situ, including contextual characteristics [11, p. 223].

This view of strategy was adopted a few years later by IS researchers who saw an opportunity to address

\footnotetext{
${ }^{2}$ For a review of the IS strategy concept, see [9] and [10].
} 
similar issues concerning IS strategy implementation [17], including the challenges of enacting IT-enabled organizational transformations through digitalization [1]. To do so, the three parameters of the S-as-P view have then been adapted to: 1) strategy practitioners as the actors who shape and actualize the IS strategy, 2) IS strategy practices as institutionalized routines that guide IS strategic activity, and 3) IS strategy praxis that is the actual activity of creating and enacting an IS strategy [23, p. 33]. In addition, the idea of praxis also refers to what it called a "strategy site" which may be conceptualized as "different bundles of IT resources, organizational structures, and practitioner roles that constitute different alignments, and undergo change, as a new praxis for digital strategizing is established" [11, p. 223].

In line with several calls made over the years concerning the challenges of DT and its underlying strategies [27], the S-as-P lens in the IS domain proposes a perspective that shifts the attention from IT use and management from a techno-centric approach to a more holistic approach [5]. Specifically, in using "rich accounts of how organizational actors rearrange messy organizational realities", notably with regard to digitalization [11, p. 222].

\subsection{Asset orchestration mechanisms for digital transformation}

Asset orchestration is a dynamic approach to resource management that goes beyond the classic value, rarity, inimitability, and non-substitutability characteristics of the resource-based view [20]. By redirecting attention on the "underexplored processes" of IT-enabled transformation [27], the asset orchestration concept provides a practical perspective to delve into the deeper structures of the DT process in many ways [3]. First, it offers a dynamic framework to study a processual and complex phenomenon that is constantly evolving. Second, it enables a more accurate identification of the mechanisms at work, by allocating, structuring, and coordinating resources at different action levels [14].

Integrating different levels of analysis concerning resources, competencies and capabilities for DT process, the IT asset orchestration mechanisms occur more specifically at three levels. First, the incremental level that contributes to the continuous improvement of the firm's basic organizational resources - through the IT resource allocation mechanism. Second, the level that allows the firm to adapt and increase its resource base, that is, through the IT resource structuration mechanism. Third, the level whose impact is felt rather on all other organizational elements (be they strategic or operational) - through the IT resource coordination mechanism [3, 14, 20].

From a practical perspective, these mechanisms reveal how the firm's digital strategy is evolving towards a holistic "fusion" of IT/IS and organizational processes and practices [6,9]. From a theoretical perspective, the same mechanisms provide a clearer understanding of managerial decisions and actions, including their articulation and relationships with other elements of the DT process [24].

\subsection{Digital transformation in SMEs}

SMEs have often been found to achieve mixed results concerning their adoption, use and management of IT. Their DT process is also seen to be more difficult than anticipated at the onset by entrepreneurs and managers [15]. Now, the DT strategy of these firms may be viewed as "a central concept to integrate the entire coordination, prioritisation, and implementation of DT within a firm" [1, p. 339]. Moreover, given the specificity of SMEs, when compared to large enterprises, with regard to their IT resources and competencies during the implementation of digital solutions [25], their relationships and partnerships with other organizations are also critical $[4,15]$. In such a context, the focus is then (re)direct on the involved actors, their decisions as well as their underlying intents [21], including their managerial practices and their derived organizational capabilities [13].

Given its theoretical appropriateness to the growing complexity of the digital world in the SMEs context, the S-as-P lens is combined in this study to the asset orchestration notion in order to put forward the specific mechanisms that allow a firm to effectively deploy, use and manage its IT and organizational resources [14, 24]. More specifically, this approach is deemed theoretically useful because it explicitly addresses how entrepreneurial and managerial actions contribute to adapt and change the resources, processes and structures that are required when firms engage in a DT process through the implementation of a coherent DT strategy $[3,27]$.

To summarize, we present in Table 1 the key concepts that have been mobilized in this study, as well as the main practical concern or research question associated to each of them. 
Table 1: Key concepts of digital transformation process through strategy-as-practice and asset orchestration lenses

\begin{tabular}{|c|c|c|}
\hline Concepts & Main concern/underlying question & $\begin{array}{c}\text { Sources } \\
\text { (adapted from) }\end{array}$ \\
\hline \multicolumn{3}{|c|}{ IS strategy concepts (for digital age) } \\
\hline $\begin{array}{l}\text { - Digital business strategy } \\
\text { (Strategic intents) }\end{array}$ & $\begin{array}{l}\text { How can digital technologies contribute to IT-value } \\
\text { creation and build the competitive advantage? }\end{array}$ & \multirow{3}{*}{$\begin{array}{l}\text { Bharadwaj et al. } \\
\text { (2013); } \\
\text { Stockhinger and } \\
\text { Teubner (2018) }\end{array}$} \\
\hline $\begin{array}{l}\text { - Digital strategy/Digital IT/IS } \\
\text { strategy (Decisions and } \\
\text { means) }\end{array}$ & $\begin{array}{l}\text { What is the potential of digital technologies? Which } \\
\text { capabilities are required to exploit their potential? }\end{array}$ & \\
\hline $\begin{array}{l}\text { - DT strategy (Enactment of } \\
\text { digital transformation) }\end{array}$ & $\begin{array}{l}\text { How to plan, govern and implement digital } \\
\text { transformation? }\end{array}$ & \\
\hline \multicolumn{3}{|l|}{ S-as-P lens concepts } \\
\hline - IS strategy practitioners & Actors who shape and actualize the IS strategy & \multirow{2}{*}{$\begin{array}{l}\text { Huang et al. } \\
\text { (2014) }\end{array}$} \\
\hline - IS strategy practices & Institutionalized routines that guide IS strategic activity & \\
\hline $\begin{array}{l}\text { - IS strategy praxis } \\
\text { (Strategy site) }\end{array}$ & $\begin{array}{l}\text { Actual activity of creating and enacting an IS strategy. } \\
\text { "Strategy site" could imply "bundles of IT resources, } \\
\text { organizational structures, and practitioner roles that } \\
\text { constitute different alignments, and undergo change, as a } \\
\text { new praxis for digital strategizing is established" }\end{array}$ & $\begin{array}{l}\text { Arvidsson and } \\
\text { Holmström } \\
\text { (2017); Huang } \\
\text { et al. (2014) }\end{array}$ \\
\hline \multicolumn{3}{|c|}{ IT asset orchestration mechanisms } \\
\hline - IT resource allocation & $\begin{array}{l}\text { Mechanism that contributes to the continuous } \\
\text { improvement of the firm's basic organizational resources. }\end{array}$ & \multirow{3}{*}{$\begin{array}{l}\text { Helfat et al. } \\
\text { (2007); Sirmon } \\
\text { et al. (2007; } \\
\text { 2011) }\end{array}$} \\
\hline - IT resource structuration & $\begin{array}{l}\text { Mechanism that allows the firm to adapt and increase its } \\
\text { resource base }\end{array}$ & \\
\hline - IT resource coordination & $\begin{array}{l}\text { Mechanism whose impact is felt rather on all other } \\
\text { organizational elements (be they strategic or operational) }\end{array}$ & \\
\hline
\end{tabular}

\section{Method}

Our revelatory case study aims to investigate a DT process in a more holistic manner so as to better describe and understand the "core" IS strategy of the selected firm $[1,2]$. To do so and answer our two research questions, we conducted a single case study in a Canadian SME, namely EngSERV, that develops and offers automated handling equipment and warehousing services.

Based on diversified empirical data sources [19, $28]$, this study adopts a case research strategy that is grounded in the interpretive paradigm [29]. Recognized as a particularly useful approach for producing comprehensive theory of IT phenomena [30], our case study method aims to reveal a contemporary phenomenon within its real-life context, especially when the boundaries between phenomenon and context are not clearly evident [28]. More precisely, through a single interpretive case study, we aim to describe the timeframe of strategic decisions and events occurring during the DT process that occurred at EngSERV, and thus adopt a contextualized approach [31]. In this regard, we do not aim to provide 'truth' or to validate an existing theory through statistical generalizations [30]. This approach offers rather the opportunity to provide a better understanding of the dynamic interactions between people and technology within the DT process studied $[26,27]$. And in doing so, we are able to present results that reveal, in more concrete manner, the challenges faced by SMEs in enacting their DT process.

\subsection{Case selection}

As asserted by Siggelkow (2007), there are three fundamental reasons to use case studies in research: motivation, inspiration, and illustration. Thus, a "revelatory" case study was conducted in an industrial service SME whose characteristics are conducive to a renewed vision of the IS strategy concept [2, 23]. For Yin (2009), a revelatory case study responds to these characteristics, but also raises issues about the selection of the case to be studied. Increasing the potential for discovery through theoretical sampling, EngSERV was selected because of its strategic history as well as its constant and high-added value adaptation to a changing business environment, and in particular because of its high technological content and its constantly growing capacity to use and manage IT in the provision of its services [32]. To do so, all key informants interviewed had to have been in their 
position for five years or more. They were thus able to provide us with rich information on EngSERV's DT strategy as well as on the impacts of this strategy on the firm's transformation process.

\subsection{Data collection and analysis}

In an interpretive qualitative research strategy, it is important "that theoretical abstractions should be carefully related to the field study details as they were experienced and/or collected by the research" [31, p. 75]. To do so, data collection was conducted through recorded semi-structured interviews with three key informants, including two owner managers, and one IT director. The interviews were conducted in situ and by phone at four different times (one initial interview of the informants, two complementary interviews, and one validation interview). A digital file containing information collected in various formats (text, audio, imagery) was also established from the firm's website and from its use of social media (Facebook, Twitter, LinkedIn). Founded on a thematic analysis [22] and a coding scheme based on the key concepts of DT process (cf. Table 1) as well as on the "strategic intent $\rightarrow$ decisions $\rightarrow$ means" sequence [13, 21 ], the analysis procedure was supported by the use of the N'Vivo software.

Considering the descriptive and comprehensive objectives of the research as well as its anchoring in practice [11], a case strategy combined with modeling techniques is useful to reveal the specific elements underpinning current events $[17,30]$. This type of tool is of interest, given the dual challenge of making intelligible a complex phenomenon and communicating such intelligibility between IS strategy researchers and practitioners [10]. Developed with graphics software, an impact schema (cf. Figure 1) went beyond a simple descriptive narrative of the DT process experienced by the EngSERV since its foundation [19]. Complemented by an event-state diagram (cf. Figure 2) which provides a timeframe presentation of our observations in relation with the identified IT orchestration mechanisms, the "strategic intent $\rightarrow$ decisions $\rightarrow$ means" sequence was useful for two reasons. The first is that it concretely illustrates the role and growing strategic importance of IT in the company's business [21]. Thus becoming the underlying link that explains how the DT process progressed strategically over time, through the adoption, use and management of IT [9]. The second purpose of this sequence is to respect our desire to approach the process studied from a truly practical point of view [12]. That is, through the S-as-P lens, in a way that allows for a better understanding of the role of the context (praxis), the actors (practitioners) and the practices involved $[11,17]$.
Such an analytical framework also allows for a richer explanation of the object of research [33], while providing the material needed to develop a detailed event narrative $[18,22]$, which facilitates the validation of the key informants' interpretations [29, 31]. Finally, and despite the study's previously-stated aim with regards to generalization [30], the methodological rigor of the study in terms of the credibility, transferability, dependability and confirmability of its results was assured in various ways [28]. These precautions include triangulation of data sources, continuous validation of research interpretations by the informants, and the establishment of a "chain of evidence" to justify research conclusions and to offer a plausible "causal" explanation of the studied phenomenon [22, 33].

\section{Results and Discussion}

Inspired by the S-as-P theoretical lens and the asset orchestration mechanism approach, the following results present EngSERV's acquisition and development of IT resources and competencies with regards to the DT process enacted over a period of ten years. These results also present the organizational capabilities derived by EngSERV over this period, through the decisions of the actors in the DT process as well as their managerial practices. The related discussion meant to provide further understanding of its underlying DT strategy.

\subsection{EngSERV's strategic portait: "praxis" and IT "allocation"}

EngServ offers engineering project services for the design of mechanical and electrical equipment, which it provides mainly to medium-sized and large manufacturers. A business ecosystem that is described as "very conservative", particularly in terms of technology adoption and use. The firm was founded in 2002 by two engineers, both acting as leaders, and counts a dozen of specialized employees, technicians and engineers, a finance manager, a director of operations who holds an MBA, and an IT director who is also responsible for procurement.

Through the allocation of various IT resources, EngSERV's DT truly began in 2010. More specifically with the acquisition and development of a more sophisticated IT infrastructure, including a more powerful integrated management system (ERP), a new optical fiber-based telecommunications network, a technical documentation management system aimed at the mechanical sector, as well as the use of a 3D printer for research and development projects. Combining different hardware and software resources, EngSERV 
was thus able to reduce redundancy and minimize the risk of errors by automating, for instance, revisions to its engineering drawings. Supported by a longstanding partnership with an external IT service firm, EngSERV's managing team was also able to optimize and better target its IT investments. The year 2013 marked the beginning of a technological acceleration characterized by the acquisition and implementation of mobile devices, such as smartphones for all employees. These devices allowed the use of different collaborative tools such as video conferencing as well as remote access, through a virtual private network (VPN), to the ERP system's data.

In terms of EngSERV's service delivery competencies, one of the two owner-managers stresses how specialists from different units of the company can now collaborate better and work more closely together for the benefit of the customer. From an operational point of view, the IT director focuses on the benefits of increased internal integration that allows access to corporate data anywhere and anytime.

Now, for most SMEs, the initial IS strategy is often to consider IT mainly as a cost center [10]. At the beginning of its activities, EndSERV did not escape this situation. Nevertheless, it is important to mention that their DT strategy was tempered by the presence of an owner manager whose interest in IT was strong. In doing so, the first phases of the DT process thus resulted in adjustments to EngSERV's human resources and IT competencies. This included a new role for the IT director in the management team. For us, this greater support from the firm's IT resources and competencies resulted in an improved organizational learning capability within its DT process.

\subsection{EngSERV's strategic sequence: "actors" and IT "structuration"}

As illustrated in Figure 1 and consistent with a DT process that aims for EngSERV "be ahead", the firm's IS strategy may be described as "IS innovator" [9]. In this regard, the managers' attitudes and behaviors are certainly the first dimension of a DT strategy that encouraged the organizational development of sensing and learning capabilities [32]. Especially with regard to the pervasive and strategic roles played by IT in the firm [21]. In other words, EngSERV's managers encouraged the initiation of the DT process through the formulation of a more coherent DT strategy, though it was not formalized [15].

The first strategic intent of EngSERV, "being ahead", combined with the second intent, "fusion of IT" (with the rest of organizational activities), allowed the firm to move from a basic IS strategy, to an IS 'master plan', and then to a DT perspective over a tenyear period [6, 9]. The presence of a leader (and owner) with great openness to the DT of his firm allowed EngSERV to envision what benefits, internal as well as competitive, it could obtain through early adoption of IT, despite the costs that this entailed. For example, the early hiring of a qualified IT/procurement manager later became IT director, the level and type of IT investment, the continuous experimentation with IT represented highly significant decisions for the company's strategic development and future success. These specific decisions thus constitute other examples of the processual elements that shape a supportive DT strategy for a successful DT process.

Now, in some specific situations such as service enterprises [16], the innovation capability takes on a broader meaning than the mere development of technological artefacts [9]. Through a more strategic management of IT, that is, through a DT strategy, firms thus tend to innovate through collaboration and experimentation carried out in wide networks that inevitably lead to spillover effects on the firm's business processes [8, 32]. More specifically, close cooperation with the leading systems developer in its sector of activity allowed EngSERV to develop advanced programming skills for its various computerized tools. In addition to providing notoriety to the firm within its business ecosystem, this collaboration led it to recombine certain services in order to develop an exclusive offer. The firm's intention was then to develop functionalities that were compatible with other developers' systems. The interoperability of the firm's products then became a way of penetrating new markets as well as consolidating existing markets. More specifically, the innovation was in finding a new way to provide, a more reliable and secure remote support to customers, whose technological infrastructure was often obsolete. This was accomplished through the structuration of existing IT resources such as a cellular network and mobile devices.

In EngSERV's case, the elements that support the transformation of the firm's IS strategy as well as the firm itself come from various sources and may be both explorative and exploitative in nature [24]. Now, the DT could not have been realized without the help of a partner specialized in networking, thus revealing another important dimension of a DT strategy in this context. As a support to the development of its IT infrastructure, external partnerships allow an industrial service SME to access a wider range of innovations that, in turn, affect the range of services offered by these firms [16]. 


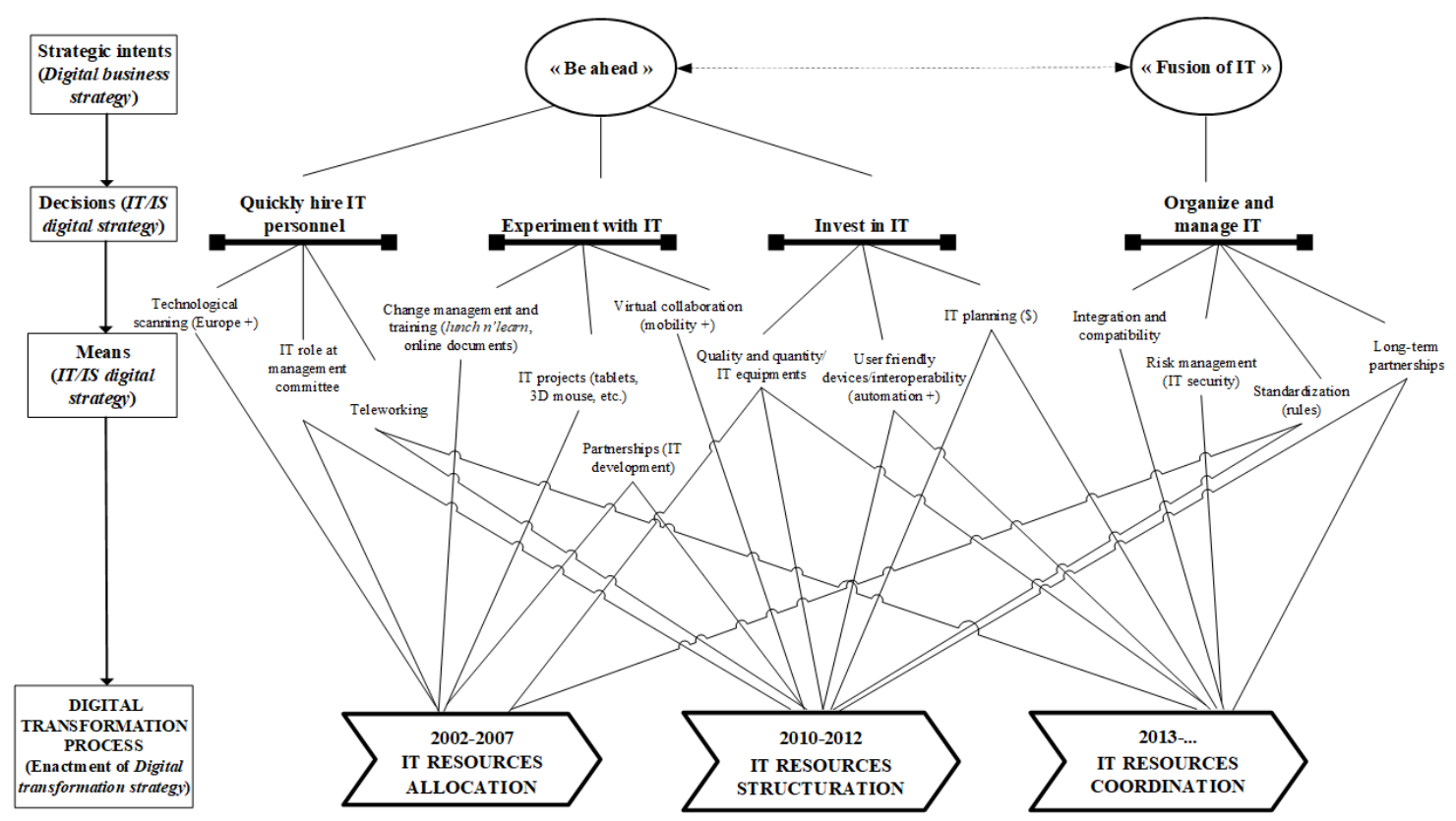

Figure 1: Emergence of EngSERV's digital transformation strategy

\subsection{EngSERV's digital transformation process: "practices" and IT "coordination"}

EngSERV's enactment of its DT process would not be possible without effective coordination mechanisms between all internal and external actors within this process. Thus, as a result of the prior decisions made by EngSERV, a variety of means have been put in place (cf. Figure 1). More specifically, we find that IT resources refer to IT staff in terms of IT competencies and specializations, IT architecture and infrastructure for flexibility, integration, compatibility, connectivity and modularity, as well as the establishment of internal and external partnerships.

While it is undeniable that IT resources and competencies constitute the foundation of the firm's DT $[1,26]$, it must be recognized that EngSERV's capability for (re)structuration were largely made possible through recurrent knowledge acquisition and assimilation practices [25]. Viewed from a transformational perspective, such means are indicative of the manner by which the firm facilitated its technological deployment through relational mechanisms based on collaboration and IT governance to better support operations and processes [2, 8]. Furthermore, the conceptualization of DT process and strategy as a reconfigurational process-based phenomenon reflects an 'open systems' approach that includes the firm's business partners and interorganizational processes and systems [9].

Returning to Figure 1, this is illustrated by the numerous and multidirectional impacts that simultaneously converge on several phases of the DT process, depending upon the events experienced the firm during this process. These complementary dimensions of organizational transformation support by IT are thus viewed as patterned managerial behaviors and decision-making rather than organizational resources or routines [4]. Completing these observations, Figure 2 illustrates the decisions (cf. rectangle forms), that focused both on the development of EngSERV's technical and managerial competencies. It is then possible to suppose that these "events" acted in a complementary manner to the emergent DT strategy in the early stages of the DT process [32]. Consequently, these decisions were seen to lead to a better flexibility and innovativeness in EngSERV's services [16].

This situation was made possible by the interoperability of the firm's IT architecture and the interweaving of its high-value-added projects with its clients' projects. In doing so, our results refer to the "integration quest" that is now moving beyond the traditional integration of systems and business processes [6, 7]. For us, this is another important dimension of DT strategy in a business environment characterized by an increasing necessity for SMEs to enact a DT process. Affected, in different ways at different times, by the interactions of its strategic intentions, decisions and means, we may then infer that the DT process was only made possible by an efficient coordination mechanism [3, 14]. 


\subsection{EngSERV's enactment of digital transformation process}

As illustrated in the temporal bracketing schema of Figure 2, the role attributed to IT by the firm is dependent upon alterations experienced in its environment, upon its strategic choices, upon the technology itself and the opportunities that it presents, and upon the firm's resource configuration $[9,25]$.

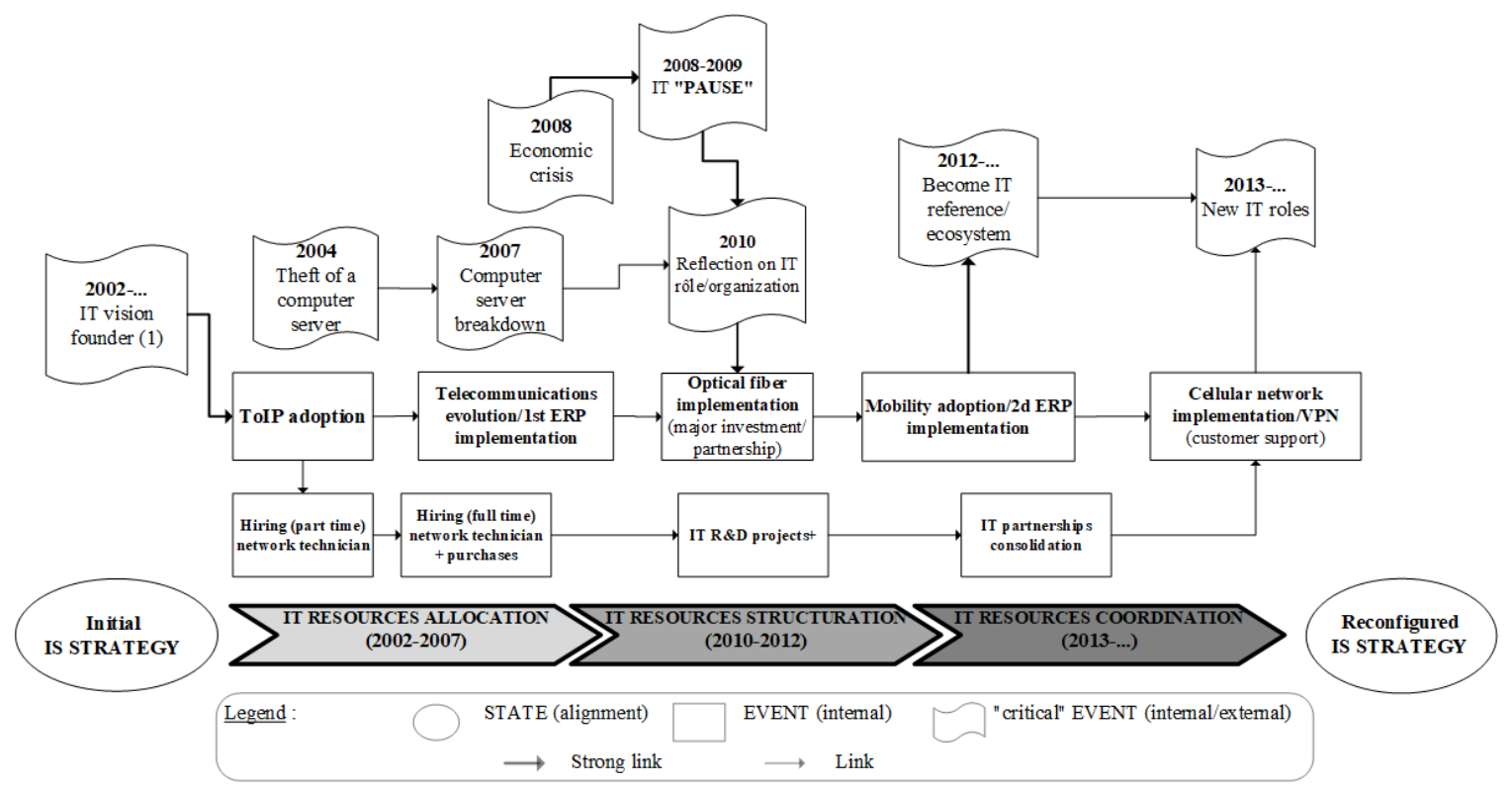

Figure 2: Event-state diagram of EngSERV's digital transformation process

In this line of thought, the IS strategy not only modifies the business processes of the firm through different mechanisms but may also contribute to redefine its business ecosystem and organizational boundaries [8]. In other words, EndSERV's DT process really begins with an answer to the "why" question. This question concerns IT adoption, and highlights the underlying intentions that guide actions taken in a given context [21]. The DT process then continues with the decisions that are in line with this strategic intention [4], and evolves through recurring managerial and IT practices [11].

Thus, in answer to our research questions, the analysis of the EngSERV case data shows that two main strategic intentions led to four important decisions which, in turn, led to the establishment of fourteen means to enact the DT process (cf. Figure 1). In order to complete these "impacts" analysis, these dimensions of DT strategy were linked to the three IT resource orchestration mechanisms in the form of a timeframe process model. In this regard, Figure 2 provides an 'event-state' diagram of EngSERV's DT process within which induction and emergence have to find their place [6]. For instance, certain events or decisions that may appear unrelated to IT, as they rather concern work organization, risk management, performance evaluation or organizational culture, should not be excluded too quickly [32]. Indeed, the inclusion of this type of interpretation of the DT strategy reconfiguration and its associated effects also helped us to overcome the limitations and biases associated to a purely "technological" perspective of the DT process [10]. This holistic perspective of the DT process and its related DT strategy can be observed through the flow of acquisition, accumulation and development of the required IT resources, competencies and capabilities [4]. In this regard, the evolution of the DT process conducted in EngSERV over time represents the starting as well as the ending point of the strategy reconfiguration in a given organizational context, in a given business environment, at a given time $[6,11]$. These observations of EngSERV's DT process may also be considered as the concrete outputs of the strategic sequence illustrated in Figure 1.

\section{Contributions to theory and practice}

The EngSERV case demonstrates how the DT process supported by an adequate DT strategy evolved in achieving greater technological coherence and ITbusiness value for the firm [8]. In this regard, our results emphasized the firm's ability to react 
adequately and in timely manner to various changes in its environment through an evolving DT strategy. Now, this strategy is not only a complex construct that captures the interaction between the needs and capabilities of the firm but, and as seen in Figure 2, it is also a flow of events and decisions within which unexpected contingencies might occur [33]. In addition, the EngSERV case allows to gain insight on the DT process as an "evolving system embedded in a complex and dynamic social context" [26]. As the main result of this revelatory case study, Figures 1 and 2 thus illustrate how the S-as-P lens allows us to 'shine a brighter light' on the different phases of the DT process, that is, on the IT asset orchestration mechanisms that enabled EngSERV to strategically manage this process.

Although exploratory in nature, our case study's theoretical contributions are threefold. First, we observed the IS strategy universe through a DT perspective by emphasizing multidimensional elements such as the context, actors and practices that complement the adoption, use and management of IT/ IS [11], and most importantly by identifying the means by which the firm creates IT-business value through its DT process [20]. Second, we were able to contextualize a "revelatory" DT process in a services context [16], more specifically in an industrial services SME context which has been understudied to-date notwithstanding its importance in the knowledgebased global economy [25]. Third, we provide a method that: 1) integrates micro- and macro-levels of analysis; 2) is well adapted to the S-as-P lens [18], and 3 ) helps us to delve into the deeper structures of the complex and dynamic phenomenon that is the implementation of IS strategy [24, 33].

From a practical view, and despite a solid number of empirical studies of IS strategy within the last thirty years, this IS research domain still presents unresolved issues. One being the lack of understanding of IS strategy implementation within the DT process [1], another being the lack of relevance and usefulness of the results of these studies for managerial practice [10]. In view of these two issues, the S-as-P theoretical lens, in combination with the asset orchestration concept, was used here to observe the DT process of an SME in the industrial services sector, and to take a renewed look at the IS strategy concept in this particular context. Our conceptual effort in this case responds to a resurging research question that regards the manner by which organizations, in the digital world, actually enact their DT strategy $[2,5]$. Thus, once broken down into specific phases supported by organizational and technological elements, and with the advantage of being "closer to the action" [17], the DT process enacted by EngSERV ensures the consistency required for IT value creation in two ways [8]. The first is by framing certain managerial and strategic decisions through a dominant logic of action and behaviors [21] that are in line with the DT strategy adopted. The second is by guiding the acquisition and development of IT resources and competencies [4] as well as their deployment through IT asset orchestration mechanisms that concern the organization as a whole [3, 14].

In line with other researchers [21, 27], these contributions also reveal how the three main 'quests' of the IS strategy research domain have evolved, namely the strategic alignment quest, the integration quest and the sustained competitive advantage quest [6]. In other words, this study highlights in a concrete manner how a DT process is enacted through a renewed look at IS strategy and its associated concepts in today's business context $[2,5]$. At the same time, our results address the challenges of digital age by proposing a perspective of the DT process as a continuous reconfiguration of the firm's business activities.

\section{References}

[1] Matt, C., T. Hess, and A. Benlian. "Digital Transformation Strategies," Business \& Information Systems Engineering, (57:5), 2015, pp. 339-343.

[2] Stockhinger, J. and R.-A. Teubner. "How Management Consultancies Make Sense of Digital Strategy," in 39th International Conference on Information Systems (ICIS). 2018. San Francisco, USA.

[3] Helfat, C.E., S. Finkelstein, W. Mitchell, M.A. Peteraf, H. Singh, D.J. Teece, and S.G. Winter, Dynamic Capabilities. Understanding Strategic Change in Organizations. 2007, Oxford, UK: Blackwell Publishing.

[4] Neirotti, P., E. Raguseo, and E. Paolucci. "How SMEs Develop ICT-Based Capabilities in Response to Their Environment: Past Evidence and Implications for the Uptake of the New ICT Paradigm," Journal of Enterprise Information Management, (31:1), 2018, pp. 10-37.

[5] Chanias, S. "Mastering Digital Transformation: The Path of a Financial Services Provider Towards a Digital Transformation Strategy," in 25th European Conference on Information Systems (ECIS). 2017. Guimarães, Portugal.

[6] Tanriverdi, H., A. Rai, and N. Venkatraman. "Research Commentary-Reframing the Dominant Quests of Information Systems Strategy Research for Complex Adaptive Business Systems," Information Systems Research, (21:4), 2010, pp. 822-834.

[7] Ross, J.W. "Creating a Strategic IT Architecture Competency: Learning in Stages," MIS Quarterly Executive, (2:1), 2003, pp. 31-43. 
[8] Bharadwaj, A., O.A. El Sawy, P.A. Pavlou, and N. Venkatraman. "Digital Business Strategy: Toward a Next Generation of Insights," MIS Quarterly, (37:2), 2013, pp. 471-482.

[9] Chen, D.Q., M. Mocker, D.S. Preston, and A. Teubner. "Information Systems Strategy: Reconceptualization, Measurement, and Implications," MIS Quarterly, (34:2), 2010, pp. 233-259.

[10] Teubner, R.A. "Information Systems Strategy," Business \& Information Systems Engineering, (5:4), 2013, pp. 243-257.

[11] Arvidsson, V. and J. Holmström, Digitalization as a Strategy Practice. What is There to Learn from Strategy as Practice Research?, in The Routledge Companion to Management Information Systems, R.D. Galliers, and Stein, M-K, Editors. 2017, Abingdon: Routledge.

[12] Jarzabkowski, P. and A. Paul Spee. "Strategy-asPractice: A Review and Future Directions for the Field," International Journal of Management Reviews, (11:1), 2009, pp. 69-95.

[13] Helfat, C.E. and J.A. Martin. "Dynamic Managerial Capabilities Review and Assessment of Managerial Impact on Strategic Change," Journal of Management, (41:5), 2015, pp. 1281-1312.

[14] Sirmon, D.G., M.A. Hitt, R.D. Ireland, and B.A. Gilbert. "Resource Orchestration to Create Competitive Advantage," Journal of Management, (37:5), 2011, pp. 1390-1412.

[15] Pelletier, C. and L.M. Cloutier. "Challenges of Digital Transformation in SMEs: Exploration of IT-Related Perceptions in a Service Ecosystem," in 52d Hawaii International Conference on System Sciences (HICSS). 2019. Hawaii, USA.

[16] Setia, P., P. Setia, V. Venkatesh, and S. Joglekar. "Leveraging Digital Technologies: How Information Quality Leads to Localized Capabilities and Customer Service Performance," MIS Quarterly, (37:2), 2013, pp. 565-590.

[17] Whittington, R. "Information Systems Strategy and Strategy-as-Practice: A Joint Agenda," The Journal of Strategic Information Systems, (23:1), 2014, pp. 87-91.

[18] Fenton, C. and A. Langley. "Strategy as Practice and the Narrative Turn," Organization Studies, (32:9), 2011, pp. 1171-1196.

[19] Siggelkow, N. "Persuasion with Case Studies," Academy of Management Journal, (50:1), 2007, pp. 20-24.

[20] Sirmon, D.G., M.A. Hitt, and R.D. Ireland. "Managing Firm Resources in Dynamic Environments to Create Value: Looking inside the Black Box," Academy of Management Review, (32:1), 2007, pp. 273-292.

[21] Kor, Y.Y. and A. Mesko. "Dynamic Managerial Capabilities: Configuration and Orchestration of Top
Executives' Capabilities and the Firm's Dominant Logic," Strategic Management Journal, (34:2), 2013, pp. 233-244.

[22] Miles, M.B., A. Huberman, and J. Saldaña, Qualitative Data Analysis: A Methods Sourcebook. $3^{\mathrm{d}}$ ed. 2014, Thousand Oaks, Califorinia: Sage Publications.

[23] Huang, J., S. Newell, J. Huang, and S.-L. Pan. "SiteShifting as the Source of Ambidexterity: Empirical Insights from the Field of Ticketing," The Journal of Strategic Information Systems, (23:1), 2014, pp. 29-44.

[24] Turner, N., J. Swart, and H. Maylor. "Mechanisms for Managing Ambidexterity: A Review and Research Agenda," International Journal of Management Reviews, (15:3), 2013, pp. 317-332.

[25] Pelletier, C. and L. Raymond. "Understanding Strategic IT Alignment from a Dynamic Capability-Based View: A Process Study in an Industrial Service Context.," in 10th SKM Symposium Competence-based Strategic management - Strategisches Kompetenzmanagement. 2017. Berlin, Germany.

[26] Orlikowski, W.J. and C.S. Iacono. "Research Commentary: Desperately Seeking the 'IT' in IT Research a Call to Theorizing the IT Artifact," Information Systems Research, (12:2), 2001, pp. 121-134.

[27] Besson, P. and F. Rowe. "Strategizing Information Systems-Enabled Organizational Transformation: A Transdisciplinary Review and New Directions," The Journal of Strategic Information Systems, (21:2), 2012, pp. 103-124.

[28] Yin, R.K., Case Study Research Design and Methods. $4^{\text {th }}$ ed. 2009, Thousand Oaks: Sage.

[29] Walsham, G. "Doing Interpretive Research," European Journal of Information Systems, (15), 2006, pp. 320-330.

[30] Gregor, S. "The Nature of Theory in Information Systems," MIS Quarterly, (30:3), 2006, pp. 611-642.

[31] Klein, H.K. and M.D. Myers. "A Set of Principles for Conducting and Evaluating Interpretive Field Studies in Information Systems," MIS Quarterly, (23:1), 1999, pp. 67-94.

[32] Khatri, N., A. Baveja, N. Agrawal, and G. Brown. "HR and IT Capabilities and Complementarities in KnowledgeIntensive Services," The International Journal of Human Resource Management, (21:15), 2010, pp. 2889-2909.

[33] Langley, A., C. Smallman, H. Tsoukas, and A.H. Van de Ven. "Process Studies of Change in Organization and Management: Unveiling Temporality, Activity, and Flow," Academy of Management Journal, (56:1), 2013, pp. 1-13. 